\title{
C-type lectins and extracellular vesicles in virus-induced NETosis
}

\author{
Pei-Shan Sung ${ }^{1}$ and Shie-Liang Hsieh ${ }^{1,2,3,4,5^{*}}$ (B)
}

\begin{abstract}
Dysregulated formation of neutrophil extracellular traps (NETs) is observed in acute viral infections. Moreover, NETs contribute to the pathogenesis of acute viral infections, including those caused by the dengue virus (DV) and severe acute respiratory syndrome coronavirus-2 (SARS-CoV-2). Furthermore, excessive NET formation (NETosis) is associated with disease severity in patients suffering from SARS-CoV-2-induced multiple organ injuries. Dendritic cell-specific intercellular adhesion molecule-3-grabbing non-integrin (DC-SIGN) and other members of C-type lectin family (L-SIGN, LSECtin, CLEC10A) have been reported to interact with viral glycans to facilitate virus spreading and exacerbates inflammatory reactions. Moreover, spleen tyrosine kinase (Syk)-coupled C-type lectin member 5A (CLEC5A) has been shown as the pattern recognition receptor for members of flaviviruses, and is responsible for DV-induced cytokine storm and Japanese encephalomyelitis virus (JEV)-induced neuronal inflammation. Moreover, DV activates platelets via CLEC2 to release extracellular vesicles (EVs), including microvesicles (MVs) and exosomes (EXOs). The DVactivated EXOs (DV-EXOs) and MVs (DV-MVs) stimulate CLEC5A and Toll-like receptor 2 (TLR2), respectively, to enhance NET formation and inflammatory reactions. Thus, EVs from virus-activated platelets (PLT-EVs) are potent endogenous danger signals, and blockade of C-type lectins is a promising strategy to attenuate virus-induced NETosis and intravascular coagulopathy.
\end{abstract}

Keywords: COVID-19, SARS-CoV-2, Dengue virus (DV), Platelet, C-type lectin receptor (CLR), CLEC2, CLEC5A, TLR, Extracellular vesicle (EV), Microvesicle (MV), Exosome (EXO)

\section{Background}

Neutrophils express abundant Toll-like receptors (TLRs) that recognize pathogen-associated molecular patterns in bacteria, viruses, and other microbes [1]. Moreover, neutrophils also express abundant spleen tyrosine kinase-coupled C-type lectin receptors (Syk-CLRs) to serve as pattern recognition receptors (PRRs) to recognize beta-glucans on fungi (Dectin-1 and Dectin-2) [2] and peptidoglycans on Listeria (spleen tyrosine kinase (Syk)-coupled C-type lectin member 5A, CLEC5A) [3]. Neutrophil-mediated immunity is via phagocytosis, release of free radicals, and other mediators to kill

\footnotetext{
*Correspondence: slhsieh@gate.sinica.edu.tw

${ }^{1}$ Genomics Research Center, Academia Sinica, 128, Academia Road, Sec. 2, Nankang District, Taipei 115, Taiwan

Full list of author information is available at the end of the article
}

microbes [4]. Recently, neutrophils are found to prevent bacteria spreading via the formation of web-like structures, known as neutrophil extracellular traps (NETs) [5]. In contrast to bacteria and fungi, viruses exist on a nanometer scale and enter cells via membrane fusion. Therefore, hosts rely on humoral immunity (antibodies) to neutralize viruses as well as cell-mediated immunity to kill virus-infected cells to prevent virus invasion. From this viewpoint, neutrophils seem dispensable, or only play a minor role, in anti-viral immunity. Thus, the significance of virus-induced NET formation in host defense is still controversial, and the molecular mechanism of virus-induced NETosis needs to be further investigated. In our recent review article, we addressed the detrimental roles of two Syk-CLRs (CLEC2 and CLEC5A) in acute viral infections [6, 7], and blockade of Syk-CLRs seems original author(s) and the source, provide a link to the Creative Commons licence, and indicate if changes were made. The images or other third party material in this article are included in the article's Creative Commons licence, unless indicated otherwise in a credit line to the material. If material is not included in the article's Creative Commons licence and your intended use is not permitted by statutory regulation or exceeds the permitted use, you will need to obtain permission directly from the copyright holder. To view a copy of this licence, visit http://creativecommons.org/licenses/by/4.0/. The Creative Commons Public Domain Dedication waiver (http://creativeco mmons.org/publicdomain/zero/1.0/) applies to the data made available in this article, unless otherwise stated in a credit line to the data. 
promising to attenuate virus-induced NETosis and injuries [8]. We would like to further address the critical roles of the Syk-CLR (CLEC2) and non-Syk-CLR (dendritic cell-specific intercellular adhesion molecule-3-grabbing non-integrin, DC-SIGN) in the release of extracellular vesicles (EVs) from virus-activated platelets (PLT-EVs), and discuss the potential roles of CLEC5A and Toll-like receptor 2 (TLR2) in PLT-EVs-mediated NETosis and tissue injuries in acute viral infections.

\section{Virus-induced NET formation}

Neutrophils comprise more than $50 \%$ of leukocytes in human peripheral blood and are the most abundant effector cells in human innate immunity. Neutrophils produce NETs, which comprise decondensed chromatin, histones, subsets of granules and cytoplasmic proteins that ensnare a variety of microbes [5]. NET release primarily occurs through a cell death process termed NETosis, which is characterized by the disassembly of the nuclear envelope, decondensation of nuclear chromatin into the cytoplasm, and mixture of the nuclear, cytoplasmic, and granular components in the cytoplasm of intact cells. At $3-8 \mathrm{~h}$ post neutrophil activation and subsequent cell death, NETs gradually expand into the extracellular space. In contrast to classical NETosis, a small population of neutrophils release NETs within minutes after exposure to Staphylococcus aureus in the absence of cell death (i.e., non-lytic NETosis) [9].

Decondensation of chromatin is one of the most important features of NETosis, and the process is dependent on the activation of protein-arginine deiminase type 4 (PAD4), an enzyme that citrullinates arginine residues of histones in nucleus [10]. The degree and specificity of citrullination seems depending on the activation of different PKC isoforms after engagement of neutrophils with various danger signals. PAD4 deficient neutrophils fail to produce NETs upon stimulation with chemokine or bacteria [10], while PAD4 deficient mice are more susceptible to Streptococcus pyogenes infection [11]. This observation demonstrates the critical role of NET formation in anti-bacterial infection. In contrast to the beneficial effects of NETs in anti-bacterial infection, excessive NET formation is detrimental in other microbial infections. NETs directly kill epithelial and endothelial cells, and excessive NETs damage pulmonary epithelium in fungal infection [11]. Moreover, excessive NETs in blood vessels provide scaffolds to promote deep vein thrombosis [9]. This observation suggests that excessive NETs not only damage vascular endothelial cells, but also promote intravascular coagulation and blood vessel occlusion.

The first report of virus-induced NET formation was observed in a macrophage-depleted mouse model infected with influenza A virus (IAV) H1N1 strain PR8
[12]. The authors found excessive neutrophil infiltration with extensive NET formation at the terminal bronchioles of mice after H1N1 infection [12]. Mechanically, the authors showed direct induction of NETosis by incubating neutrophils with IAV-infected LA-4 epithelial cells (multiplicity of infection/MOI $=20$ ) for $5 \mathrm{~h}$, followed by incubation with neutrophils for $150 \mathrm{~min}$ [12]. This study indicates that excessive NET formation after H1N1 infection contributes to acute lung injury and acute respiratory distress syndrome (ARDS). However, whether virus per se can activate neutrophils and induce robust NET formation is not addressed in this study. Another study demonstrated that intranasal inoculation of IAV induced NET formation and alveolar damage, which was further enhanced by secondary bacterial infection [13]. Later findings also revealed that a high level of NETs correlated with poor prognosis in severe influenza infections [14]. These observations suggest that excessive NET formation may contribute to the pathogenesis of acute lung injury in IAV-induced pneumonia. However, the latter two studies did not demonstrate whether incubation of neutrophils and IAV could induce NET formation in vitro.

Saitoh et al. later demonstrated that incubating pseudotyped human immunodeficiency virus-1 (HIV-1) with human neutrophils for $24 \mathrm{~h}$ induced the formation of multilobulated structures comprising DNA-based fibers, suggesting that HIV-1 induced NET formation in vitro. To understand how HIV-1 triggered NET formation, cells were treated with bafilomycin A1 to inhibit $\mathrm{H}^{+}$-ATPase, which is essential for endosomal TLR activation [15]. Inhibition of HIV-1-induced NET formation by bafilomycin A1 led the authors to conclude that the activation of endosomal TLR7 and TLR8 mediated HIV-1-induced NET formation. The authors further demonstrated that NETs captured HIV-1 and promoted HIV-1 elimination, indicating NET formation is beneficial to host by inhibiting viral infection and spreading. Nevertheless, the authors did not demonstrate that HIV-1 could induce NET formation in vivo. Because NET formation usually occurs at 90 min after incubation with $S$. aureus, immune complexes, or phorbol myristate acetate (PMA) [16], the extremely slow kinetics $(24 \mathrm{~h})$ of HIV-1-induced NET formation suggests that HIV-1 is a very weak inducer of NET formation in vitro. Intriguingly, the authors also demonstrated that HIV-1 induced DC-SIGN-dependent IL-10 production to counteract NET formation. Thus, whether HIV-1-induced NET formation is beneficial to host needs to be further investigated.

In contrast to the slow kinetics of HIV-1-induced NET formation, human respiratory syncytial virus (RSV) and hantaan virus (HTNV) induce NET formation within $3-8 \mathrm{~h}$ in vitro $[17,18]$, while myxoma virus (MYXV) induces NET formation within $8 \mathrm{~h}$ after injection to mice 
[19]. Cortjens et al. demonstrated that a 3-h incubation of human RSV with neutrophils induces mild non-cytolytic NETs comprising loose web-like DNA networks overlaid with elastase and citrullinated histone in vitro [17]. Interestingly, stronger NET formation was observed in the airways and lungs of children after RSV infection. Moreover, the extent of NET formation correlates with the severity of lower respiratory tract disease after RSV infection. Therefore, the authors concluded that exaggerated NET formation contributed to airway obstruction, and played a detrimental role in RSV infection. Furthermore, Sung et al. demonstrated that dengue virus (DV) induced NET formation via inducing platelet-derived EVs, and blockade of NET formation reduced DV-induced hemorrhagic shock [20]. Recently, NET formation is shown as a disease severity marker in COVID-19 patients [21], and contributes to the pathogenesis of severe acute respiratory syndrome coronavirus-2 (SARS-CoV-2) infection, including acute lung injury [22, 23], neuroinflammation [24], and vascular occlusion [25-27]. As SARS-CoV-2 triggers NETs to mediate COVID-19 pathology [28], it is crucial to understand the molecular mechanism of SARS-CoV2-induced NET formation for the development of better therapeutic strategy in the future [29]. The kinetics of NET formation among various viruses are summarized in Table 1 [12, 13, 15, 17-21, 30].

\section{Activated platelets in NET formation}

While virus alone is a weak inducer of NET formation in vitro, viral infection can induce substantial NET formation in vivo. This observation suggests that other cells may participate in virus-induced NET formation. Platelets are derived from myeloid precursors and are regarded as key players in hemostasis and thrombosis. Similar to other myeloid cells, platelets express abundant pattern recognition receptors, including TLRs and SykCLRs. Several reports suggest that activated platelets can induce NET formation in various model systems.

\section{Thrombin-activated platelets promote NET formation}

Although thrombin receptor-activating peptide (TRAP, a PAR-1 agonist) has no effect on NET formation, incubation of TRAP-activated platelet with neutrophils induces robust NETs in vitro [31]. In addition, excessive NETs contribute to transfusion-related acute lung injury (TRALI), and inhibition of platelet activation by aspirin or glycoprotein IIb/IIIa inhibitors decreases NET formation and attenuates lung injury [31]. Taken together, these observations indicate that activated platelet play a critical role in TRALI. Because TRAP-1 activated $H m g b 1^{-1-}$ platelets are far less potent inducers of NET formation compared to wild-type platelets, NET formation by thrombin-activated platelets is likely mediated by high mobility group box 1 (HMGB1) [32]. Intriguingly, incubation of HMGB1 protein with neutrophils does not induce NET formation in vitro, suggesting HMGB1 is just one of the components of platelet-released NET inducer.

\section{Microbe-activated platelets promote NET formation}

Activation of platelets during infections is not only able to enhance leukocyte functions and NET formation via direct and indirect interactions, but also contributes to pathogen-induced tissue injury [33]. Several bacteria have been shown to interact and activate platelets via glycoprotein (GP)IIb-IIIa, GPIb $\alpha$, Fc $\gamma$ RIIa, complement receptors, and TLRs [34]. In addition, lipopolysaccharide (LPS)-activated platelets interact with neutrophils to induce strong NET formation both in vitro and in vivo [35]. However, it is still unclear how virus-activated platelets induce NET formation.

Influenza virus infection frequently causes excessive neutrophil-platelet aggregates and NET formation in lung, thereby contributes to severe lung pathological changes [36]. It has been demonstrated that IAV activates platelets via TLR7 to release complement component 3 (C3) to induce NET formation in a mouse model [37]. Addition of C3 $(30 \mathrm{ng} / \mathrm{ml})$ to neutrophils induces NET formation in vitro, suggesting TLR7 plays a critical role in HIV-1-induced platelet aggregation, C3 releasee, and NET formation [37]. However, considering the high level of $\mathrm{C} 3(0.8-1.6 \mathrm{mg} / \mathrm{ml})$ in human serum, the pathological roles of platelet-derived C3 $(30 \mathrm{ng} / \mathrm{ml})$ in IAV-induced NET formation need to be further validated.

\section{Platelets and EVs}

In addition to complement, DV can activate platelets to release EVs (also known as microparticles) [38] to promote DV-induced inflammatory reactions and NET formation significantly [20]. While all cell types can produce EVs, platelets are the major source of circulating EVs in sera [39]. EVs are heterogeneous groups of cell-derived membranous structures, and the typical size range of EVs is between 50 and $500 \mathrm{~nm}$. Based on the origins and size, EVs are divided into exosomes (EXOs) and microvesicles (MVs). EXOs (50-150 nm) are originated from endosomes, while MVs (average 50-500 nm, up to $1-10 \mu \mathrm{m})$ are derived from plasma membrane [40]. In addition to lipid and proteins in the lipid-bilayer membrane, EVs contain various kinds of macromolecules, including enzymes, beta-catenin, G proteins, 14-3-3, chaperons, microRNA, non-coding RNA, mRNA, and DNA. Once released from cells, EVs deliver these molecules to target cells via membrane fusion or internalization after binding membrane receptors. Furthermore, EVs bind to integrins, proteoglycans, lipid-binding 


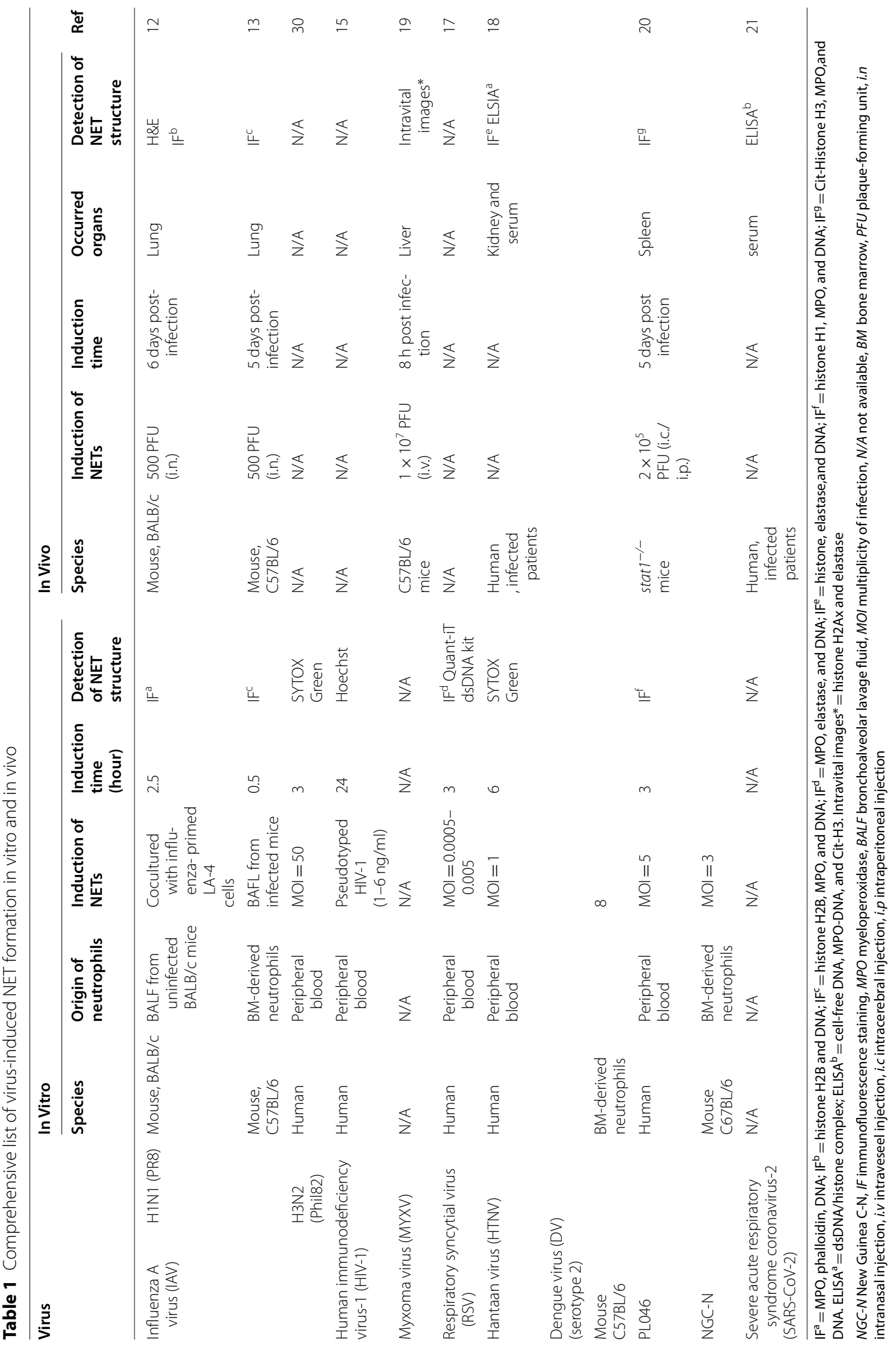


proteins, and phosphatidylserine receptor TIM4 to initiate intracellular signaling cascades. Therefore, EVs were considered as an alternative mechanism for intercellular communications [41] and activation of intracellular signaling cascades.

\section{EVs from virus-infected cells}

EVs released from virus-infected cells contain virus- and host-derived factors to facilitate virus spreading. For example, several enveloped viruses, such as HIV-1 and hepatitis viruses $\mathrm{B}, \mathrm{C}$ (HBV, HCV) utilize the endosomal sorting complexes required for transport (ESCRTs) to pack viral components to facilitate virus transmission. Moreover, EVs can spread viral docking receptors to promote viral infectivity or inhibit anti-viral responses [42-44]. These observations suggest that EVs from virusinfected cells play critical roles in intercellular communications, and may help viruses to escape from host immunosurveillance and promote transmission by hiding their genome in EVs.

\section{EVs from virus-activated platelets}

While EVs from platelet-rich plasma (PRP) promotes cell proliferation and tumor progression [45], EVs from complement-activated platelets posse procoagulant activity [46], suggesting complements play detrimental role in NETs-mediated effects Further studies indicated PLT-EVs also participate in intracellular communication, angiogenesis, tumor progression, inflammation, immunoregulation, and cellular prion protein transport [45].

In the past, research attention focused on EV-mediated delivery of proteins and RNAs to dendritic cells, and investigated their effects to enhance antigen presentation and modulate cell activity [47]. However, PLT-EVs also carry proinflammatory cytokines and contribute to fibrin deposition and joint inflammation in rheumatoid arthritis patients [48]. Recent studies further demonstrate that virus-activated platelets release EVs to enhance NET formation via activation of $\mathrm{C}$-type lectins. [49-51].

\section{C-type lectins and NET formation}

Viruses not only utilize various types of specific entry receptors to invade cells, but also engage with target cells via glycan-lectin interactions. The conventional carbohydrate-recognition domain (CRD) with EPN (Glu-Pro-Asn) tripeptide motif binds mannose (Man), $\mathrm{N}$-acetylglucosamine (GlcNAc), glucose (Glc), and L-fucose (Fuc), while CRDs with QPD (Glu-Pro-Asp) tripeptide motif binds galactose (Gal) and N-acetylgalactosamine (GalNAc) [52, 53]. Many reports have shown that viruses can interact with lectins in immune cells via terminal glycans on the virus surface[54-57]. Viral glycan-lectin interaction is not only involved in virus entry, but also plays a very important role in activating immune cells and triggering inflammatory reactions. Among members of the human C-type lectin family, DC-SIGN, L-SIGN, LSECtin, CLEC10A [58], as well as the Syk-coupled C-type lectins CLEC5A and CLEC2 [20], have been shown to play critical roles in virus-induced inflammation and NETosis.

\section{C-type lectins in platelets}

Among the C-type lectin family, DC-SIGN and the CLEC2 are highly expressed in platelets. While DC-SIGN is expressed in platelets and most of the myeloid cells [59], CLEC2 is expressed specifically in human platelets and megakaryocytes [60, 61].

\section{DC-SIGN}

DC-SIGN is the best-studied EPN-containing C-type lectin, and is highly expressed in myeloid cells, including macrophages, dendritic cells, neutrophils, and platelets [62]. Previous reports show that the specific interactions between DC-SIGN and viruses depend on the viral glycans and the CRD of DC-SIGN [63-73]. DC-SIGN forms a homo-tetramer and interacts with several glycans, including high-mannose, Lewis $\mathrm{a} / \mathrm{b} / \mathrm{x} / \mathrm{y}$, and fucosyl biantennary $\mathrm{N}$-glycans[74]. DC-SIGN is also reported to interact with several viruses to facilitate virus spread, infection, and stimulation of inflammatory reactions. For example, HIV-1 binds platelets via DC-SIGN to facilitate virus spread $[60,75,76]$. Moreover, DC-SIGN also interacts with the DV [77], West Nile virus (WNV) [66], Japanese encephalomyelitis virus (JEV) [78], Lassa virus (LVs) [79], measles virus (MVs) [80], H5N1 IAV [81], and feline coronaviruses[82] to facilitate virus entry into dendritic cells. Recent studies further demonstrate that DC-SIGN facilitates the entry of the New World arenavirus, Junin virus [83], and Rift Valley Fever (RVF) virus [63] into host cells, and act as an attachment-promoting receptor to boost Ebola virus entry into B cell lines [83-85]. Moreover, HCV interacts with DC-SIGN to escape lysosomal degradation [86]. Because the cytoplasmic domain of DC-SIGN does not contain motifs for signal transduction, it is unlikely that viruses can activate platelets directly via DC-SIGN.

\section{CLEC2}

CLEC2 is a Syk-CLR that is specifically expressed in human platelets. Human CLEC2 encodes a 229-amino acid type II transmembrane protein, comprising a C-type lectin domain in the C-terminus, and a single YxxL motif (hemITAM) in the intracellular domain located at the $\mathrm{N}$-terminus $[60,61]$. In contrast to conventional C-type lectins, CLEC2 does not contain an EPN or a QPD tripeptide motif in its CRD domain. Nevertheless, CLEC2 
is reported to bind various glycans, including sulfated $\mathrm{N}$-acetyl lactosamine (LacNAc), sulfated lactose (Lac), poly 2-8-linked $\mathrm{N}$-acetyl neuraminic acid (NeuAc), high-mannose, and sialyl-LacNAc/Lac/Lewis a[74, 87, 88]. A recent study further demonstrates that CLEC2 can bind sulfated polysaccharides fucoidans specifically [89]. While O-linked glycoprotein podoplanin is the only known endogenous ligand of CLEC2, snake venom aggretin (rhodocytin) from Calloselasma rhodostoma is shown to induce platelet activation and aggregation via CLEC2 $[61,90]$. Studies from CLEC2 knockout mice further suggest that CLEC2 is required for blood/lymphatic vessel separation during embryo development $[91,92]$. In addition, CLEC2 is responsible for immunothrombosis in bacterial infections [93, 94], and CLEC2 deficiency increases susceptibility to LPS-induced sepsis [95]. Furthermore, CLEC2 interacts with DC-SIGN to capture HIV-1 and facilitates its dissemination in infected patients [60]. Our recent study demonstrates that DV activates platelets via CLEC2 to release EVs [20], despite very low interaction between CLEC2 and DV [54]. This observation suggests that viruses can be captured by DCSIGN to facilitate virus binding and activating platelets via CLEC2.

\section{CLEC2 is critical in virus-induced EV release}

A recent study by Sung et al. demonstrates that DV activates platelets to upregulate the release of $\mathrm{CD}_{2} \mathrm{P}^{+} \mathrm{CD}^{+}{ }^{+} \mathrm{EVs}$, including DV-activated EXOs (DVEXOs) and MVs (DV-MVs). Addition of anti-CLEC2 $\mathrm{mAb}$ abolishes DV-EV release from human platelets, indicating CLEC2 is required for DV-induced EV release. The authors further separate DV-EVs into DV-EXOs and DV-MVs, and find that DV-EXOs-induced NET formation is inhibited by antagonistic anti-CLEC5A mAb, while DV-MVs-induced NET formation is inhibited by anti-TLR2 $\mathrm{mAb}$. This observation suggests that DVEXOs and DV-MVs activate CLEC5A and TLR2, respectively, to enhance NET formation and proinflammatory cytokines release from macrophages[20]. Thus, EVs from DV-activated platelets can act as endogenous 'danger signals' to enhance inflammatory reactions via activation of CLEC5A and TLR2. Furthermore, incubation of DV-EVs with endothelial cells increased permeability changes, whereas blocking the interactions between DVEVs and CLEC2 not only inhibited NET formation and attenuated systemic permeability change in vivo, but also protected mice from DV-induced lethality dramatically (>90\% protection rate) [20]. Because several viruses have been shown to interact with DC-SIGN, to form multivalent heterocomplex with CLEC5A and mannose receptor (MR), respectively [96], it would be interesting to investigate whether DC-SIGN also associates with CLEC2 to form CLEC2/DC-SIGN heterocomplex in platelets, therefore allows viruses to activate CLEC2 to induce EV release via binding to CLEC2/DC-SIGN heterocomplex.

To identify the protein ligands on DV-EVs, Sung et al. harvested EVs from DV- and aggretin (CLEC2 ligand)-activated platelets, and subjected these samples to mass spectrometry analysis [20]. The authors found that cytoskeleton components (vinculin), guanine nucleotide-binding protein (GNG3), tribbles homolog 1 (TRIB1), coagulation factor XIIIa chain (F13A1), and calnexin (CANX, an endoplasmic reticulum chaperone) were upregulated by both aggretin and DV, suggesting that these molecules are under the regulation of CLEC2-mediated signaling. Previously, cytoskeletal $\mathrm{F}$-actin is identified as a ligand for C-type lectin member 9A (CLEC9A)[97], and chaperone HSP70 is shown as a ligand for TLR2 and TLR4[98]; therefore, these upregulated components may be responsible for DVEVs-induced inflammatory reactions during viral infection. It would be interesting to ask whether the proteins upregulated in DV-MVs and DV-EXOs are also found in platelet-derived EVs after incubation of platelets with other members of flaviviruses (such as JEV and WNV) in the future. Moreover, DV infection may cause modulate glycan synthesis in platelets, thus it would be crucial to compare the glycan profile of $\mathrm{EV}$ from resting and DV-activated platelets, thereby identify the potential EV glycan ligands to CLEC5A and TLR2. As circulating platelet-derived EVs are a hallmark of SARS-CoV-2 infection [99], it would be interesting to text whether COVID19 patients' EVs can activate platelets via protein and glycan ligands to induce NET formation in the future.

\section{CLEC5A is a Syk-CLR critical in virus-induced NETosis}

Several Syk-CLRs have been identified in neutrophils, including CLEC7A (Dectin-1), CLEC6A (Dectin-2), CLEC4E (Mincle), and CLEC5A (MDL-1)[100]. Among these four Syk-CLRs, CLEC5A is shown to be responsible for Listeria monocytogenes- and DV-induced NETosis and macrophage activation $[3,20]$.

\section{CLEC5A}

CLEC5A is abundantly expressed in neutrophils, monocytes, macrophages, osteoclasts, microglia, and dendritic cells. CLEC5A serves as a pattern recognition receptor for DV [54, 101, 102], JEV[103], and the IAV [104]. Furthermore, CLEC5A is responsible for DV-induced hemorrhagic fever (DHF) and dengue shock syndrome (DSS), which represent the most severe responses to DV infection and are characterized by plasma leakage due to increased vascular permeability [54]. Injection of anti-CLEC5A monoclonal antibodies $(\mathrm{mAb})$ can reduce mortality (from 100 to $40 \%-50 \%$ ) in mice subjected to 
a lethal-dose DV challenge [54]. Similarly, blockade of CLEC5A prevents JEV-induced permeability changes in the blood-brain barrier, and protects mice from neuroinflammation and mortality[103]. These observations suggest that CLEC5A is a promiscuous pattern recognition receptor to viruses[7], and plays as a pathogenic host factor in flaviviral and influenza virus-induced inflammatory reactions.

Because direct interactions between CLEC5A and DV is weak [105], the beneficial effect of anti-CLEC5A mAb is not only mediated by inhibiting DV-CLEC5A interactions, but also by blocking interactions between CLEC5A and its endogenous danger signals. Even though the nature of CLEC5A endogenous ligands is not been characterized yet, CLEC5A-deficient mice are resistant to collagen-induced autoimmune arthritis [106] and concanavalin A-induced acute hepatitis. [107]. These observations suggest that CLEC5A can recognize endogenous danger signals, and is involved in the pathogenesis of autoimmune diseases.

\section{CLEC5A/TLR2 heterocomplex in EVs-induced NETosis and inflammation}

To understand whether CLEC5A and TLR2 also contribute to DV-EVs-induced NET formation, Sung et al. incubated DV-EVs with neutrophils pretreated with anti-CLEC5A mAb and anti-TLR2 mAb. While DV-EVsinduced NET formation was partially inhibited by antiCLEC5A mAb or anti-TLR2 mAb, co-administration of anti-CLEC5A mAb and anti-TLR2 mAb almost completely abolished DV-EVs-induced NETosis and inflammatory reactions[20]. The authors further asked whether blockade of CLEC5A and TLR2 is beneficial to host after DV infection in vivo. To address this question, stat $1^{-/-}$ mice and $\operatorname{stat1}^{-/-} \operatorname{clec} 5 \mathrm{a}^{-/-}$mice were challenged with lethal dose of DV, followed by anti-TLR2 mAb injection. While blockade of TLR2 alone was ineffective in DVchallenged stat $^{-/-}$mice, anti-TLR2 mAb reduced DVinduced NET formation and increased the survival rate of DV-challenged stat $1^{-/-}$clec $5 a^{-/-}$mice from 40 to $90 \%$ [20]. This observation suggests that simultaneous blockade of CLEC5A and TLR2 not only reduced NET formation in vivo, but also protected mice from DV-induced hemorrhagic shock and lethality [21]. Thus, DV-EVs are potent NET inducers, and simultaneous blockade of CLEC5A and TLR2 by bi-specific mAbs may be able to abolish virus-induced NET formation, and protect host from virus-induced lethality [8].

It has been shown that engagement of macrophages or neutrophils with $L$. monocytogenes induces colocalization and co-activation of CLEC5A and TLR2 [3]. Co-activation of CLEC5A and TLR2 by L. monocytogenes induced p38 kinase and AKT kinase activation, leading to robust
NET formation in neutrophils as well as inflammasome (NALP3, NLRC4, AIM2) activation and proinflammatory cytokine (IL-1 beta, TNF, CCL2, IL-17 alpha) production in macrophages [3]. Because DV-EVs can activate CLEC5A and TLR2 to induce NET formation and proinflammatory cytokine release, simultaneous blockade of CLEC5A and TLR2 by a bi-specific mAb may be able to protect host from DV-EVs-induced NETosis and inflammatory reactions during viral infections.

\section{C-type lectins in the pathogenesis of COVID-19 virus infections}

While endosomal TLRs are the most potent pattern recognition receptors to viral nucleic acids and are critical in virus-induced interferon production, members of C-type lectins are shown to exacerbate proinflammatory responses in viral infections [20],[58]. Even though viral and endogenous ligands of most C-type lectins need to be further characterized, EVs from virus-activated platelets may act as common endogenous ligands for members of C-type lectins. Recent studies demonstrate that the spike protein of SARS-CoV-2 contains $22 \mathrm{~N}$-linked glycans, including oligomannose, afucosylated and fucosylated hybrid and complex glycans [108]. Thus, it would be interesting to ask whether SARS-CoV-2 activates SykCLRs via viral glycans to induce EV release, NET formation, and proinflammatory reactions.

It is interesting to note that EV serum level increased in COVID-19 patients, and correlates with clinical symptoms and lethality $[99,109,110]$. It has been shown that platelets and neutrophils were highly activated, and dysregulated immunothrombosis associated with respiratory failure and coagulopathy was observed in COVID-19 patients. Moreover, incubation of platelet-rich plasma from COVID-19 patients with neutrophils from healthy donor induced robust NET formation [111]. Furthermore, elevated levels of cell-free DNA, myeloperoxidase, and citrullinated histone are noted in the sera of COVID19 patients, and serum NET amounts correlated with disease severity $[112,113]$. These observations suggest that SARS-CoV-2 may activate platelets to release EVs, thereby induce NET formation and cause thrombosis in COVID-19 patients. This speculation is in accord with the increased NET formation in acute lung injury (ALI) caused by SARS-CoV-2 infection [21].

It is also interesting to note that severe pulmonary inflammation in COVID-19 patients is associated with thrombotic complications, such as microangiopathy and pulmonary embolism $[114,115]$. As virus-activated platelets form aggregation with neutrophils, platelet-specific CLEC2 may contribute a significant role in SARS-CoV2-induced immunothrombosis. It has been shown that lung is responsible for $50 \%$ of platelet biogenesis or 10 


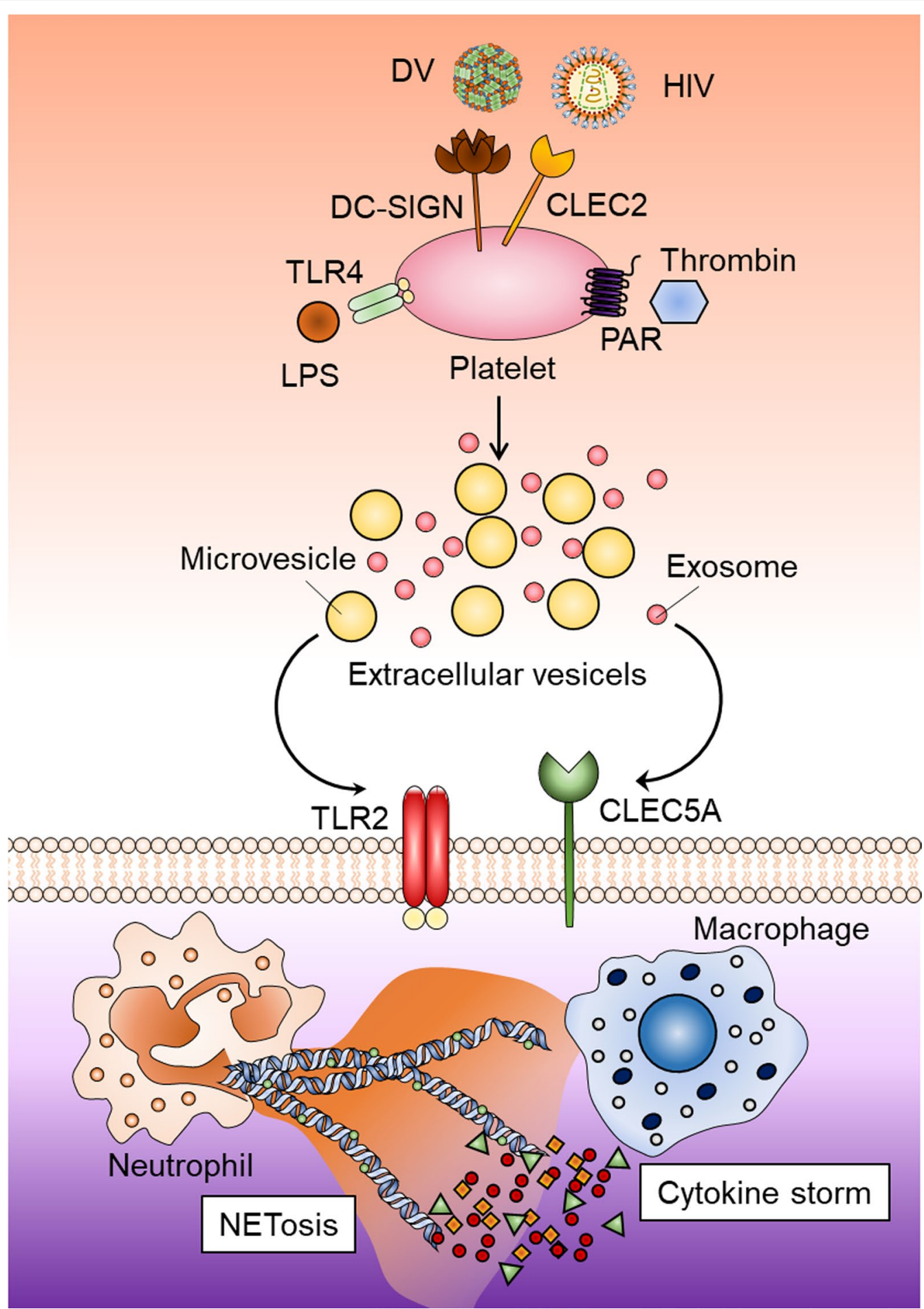

Fig. 1 Platelets play a central role in virus-induced NET formation and proinflammatory cytokine release. Dengue virus (DV) and immunodeficiency virus type I (HIV-1) interact with DC-SIGN and CLEC2. While DV, LPS, and thrombin can activate platelets to release extracellular vesicles, including exosomes and microvesicles, it is still unclear whether HIV-1 can activate platelets to release EVs. DC-SIGN may associate with CLEC2 to form DC-SIGN/CLEC2 heterocomplex in platelets, thus facilitate platelets to capture various viruses to activate platelets via CLEC2. Platelet-derived exosomes and microvesicles further activate CLEC5A and TLR2, respectively, to enhance DV-induced NET formation and proinflammatory cytokine release. Thus, EVs from activated platelets may serve as common endogenous danger signals to induce NET formation and inflammatory reactions in various microbial infections 
million platelets per hour [116], thus SARS-CoV-2 may activate platelets in lung to release EVs, thereby contributes to ARDS and intravascular coagulopathy. It would be very interesting to ask whether SARS-CoV-2 also activates platelets via CLEC2 to release EVs, and whether blockade of CLEC2 is beneficial to COVID-19 patients in the future.

\section{Concluding remarks and perspectives}

EVs have been implicated in regulation of infectious and autoimmune diseases, but the underlying molecular mechanisms are still unclear. We have demonstrated that platelets secrete EVs after incubation with DV, LPS, and thrombin. Interestingly, all the (PLT-EVs can activate CLEC5A/TLR2 heterocomplex to enhance NET formation and induce the release of IL-1 $\beta$ and other proinflammatory cytokines from macrophages[20] (Fig. 1). This observation suggests the EVs can act as endogenous danger signals to stimulate inflammatory reactions via activating CLEC5A/TLR2 heterocomplex, and blockade of CLEC5A/TLR2-mediated signaling would be able to reduce PLT-EVs-induced inflammatory reactions. It will be very interesting to investigate whether blockade of CLEC5A and TLR2 simultaneously is able to abolish virus-induced inflammatory reactions and inhibit intravascular coagulopathy in COVID-19 patients in the future $[6,20,29,50]$.

\begin{abstract}
Abbreviations
DC-SIGN: Dendritic cell-specific intercellular adhesion molecule-3-grabbing non-integrin; DV: Dengue virus; DV-EXOs: DV-activated EXOs; DV-MVs: DVactivated MVs; EXOs: Exosomes; EVs: Extracellular vesicles; PLT-EVs: EVs from virus-activated platelets; NETs: Neutrophil extracellular traps; JEV: Japanese encephalomyelitis virus; MR: Mannose receptor; MVs: Microvesicles; LacNAc: $\mathrm{N}$-acetyl lactosamine; NeuAc: N-acetyl neuraminc acid; NETosis: NET formation; SARS-CoV-2: Severe acute respiratory syndrome coronavirus-2; CLEC5A: Spleen tyrosine kinase (Syk)-coupled C-type lectin member 5A; CLEC2: Spleen tyrosine kinase (Syk)-coupled C-type lectin member 5A; Syk-CLRs: Spleen tyrosine kinase-coupled C-type lectin receptors; TLR2: Toll-like receptor 2.
\end{abstract}

\section{Acknowledgements}

We thank Dr. Fu-Tong Liu for his critical comment on this manuscript.

\section{Authors' contributions \\ SLH and PSS: text writing, PSS: illustration, table preparation, discussion. All authors read and approved the final manuscript.}

\section{Funding}

This work was supported by Academia Sinica (107-2101-01-18-03, AS-IA109-L02), Translational Medical Research Program (AS-TM-108-02-10), and Biotechnology Research Park Translational Project (AS-BRPT-110-02).

\section{Availability of supporting data}

Not applicable.

\section{Declarations}

Ethics approval and consent to participate Not applicable.
Consent for publication

Not applicable.

\section{Competing interests}

The authors declare that they have no competing interests.

\section{Author details}

${ }^{1}$ Genomics Research Center, Academia Sinica, 128, Academia Road, Sec. 2, Nankang District, Taipei 115, Taiwan. ${ }^{2}$ Institute of Clinical Medicine, National Yang Ming Chiao Tung University, Taipei, Taiwan. ${ }^{3}$ Department of Medical Research, Taipei Veterans General Hospital, Taipei, Taiwan. ${ }^{4}$ Institute for Cancer Biology and Drug Discovery, Taipei Medical University, Taipei, Taiwan. ${ }^{5}$ Institute of Immunology, College of Medicine, National Taiwan University, Taipei, Taiwan.

Received: 31 December 2020 Accepted: 8 June 2021

Published online: 11 June 2021

References

1. Gordon S, Pluddemann A, Mukhopadhyay S. Plasma membrane receptors of tissue macrophages: functions and role in pathology. J Pathol. 2020:250(5):656-66.

2. Brown GD, Herre J, Williams DL, Willment JA, Marshall AS, Gordon S. Dectin-1 mediates the biological effects of beta-glucans. J Exp Med. 2003;197(9):1119-24

3. Chen ST, Li FJ, Hsu TY, Liang SM, Yeh YC, Liao WY, Chou TY, Chen NJ, Hsiao M, Yang WB, Hsieh SL. CLEC5A is a critical receptor in innate immunity against Listeria infection. Nat Commun. 2017;8(1):299.

4. Rosales C, Lowell CA, Schnoor M, Uribe-Querol E. Neutrophils: Their Role in Innate and Adaptive Immunity 2017. J Immunol Res. 2017:2017:9748345.

5. Brinkmann V, Reichard U, Goosmann C, Fauler B, Uhlemann Y, Weiss DS, Weinrauch Y. Zychlinsky A Neutrophil extracellular traps kill bacteria. Science. 2004;303(5663):1532-5.

6. Sung PS, Hsieh SL. CLEC2 and CLEC5A: pathogenic host factors in acute viral infections. Front Immunol. 2019;10:2867.

7. Sung PS, Chang WC, Hsieh SL. CLEC5A: a promiscuous pattern recognition receptor to microbes and beyond. Adv Exp Med Biol, 2020;1204:57-73.

8. Schulz C, Gabriel G, von Kockritz-Blickwede M. Detrimental role of neutrophil extracellular traps during dengue virus infection. Trends Immunol. 2020;41(1):3-6.

9. Papayannopoulos V. Neutrophil extracellular traps in immunity and disease. Nat Rev Immunol. 2018:18(2):134-47.

10. Wang Y, Wysocka J, Sayegh J, Lee YH, Perlin JR, Leonelli L, Sonbuchner LS, McDonald CH, Cook RG, Dou Y, et al. Human PAD4 regulates histone arginine methylation levels via demethylimination. Science. 2004:306(5694):279-83.

11. Li P, Li M, Lindberg MR, Kennett MJ, Xiong N, Wang Y. PAD4 is essential for antibacterial innate immunity mediated by neutrophil extracellular traps. J Exp Med. 2010;207(9):1853-62.

12. Narasaraju T, Yang E, Samy RP, Ng HH, Poh WP, Liew AA, Phoon MC, van Rooijen N. Chow VT. Excessive neutrophils and neutrophil extracellular traps contribute to acute lung injury of influenza pneumonitis. Am J Pathol. 2011;179(1):199-210.

13. Narayana MA, Narasaraju T, Rai P, Perumalsamy R, Tan KB, Wang S, Engelward B, Chow VT. In vivo and in vitro studies on the roles of neutrophil extracellular traps during secondary pneumococcal pneumonia after primary pulmonary influenza infection. Front Immunol. 2013;4:56.

14. Zhu L, Liu L, Zhang Y, Pu L, Liu J, Li X, Chen Z, Hao Y, Wang B, Han J, et al. High level of neutrophil extracellular traps correlates with poor prognosis of severe influenza a infection. J Infect Dis. 2018;217(3):428-37.

15. Saitoh T, Komano J, Saitoh Y, Misawa T, Takahama M, Kozaki T, Uehata T, Iwasaki H, Omori H, Yamaoka S, Yamamoto N, et al. Neutrophil extracellular traps mediate a host defense response to human immunodeficiency virus-1. Cell Host Microbe. 2012;12(1):109-16.

16. van der Linden $\mathrm{M}$, Westerlaken GHA, van der Vlist $\mathrm{M}$, van Montfrans $J$, Meyaard L. Differential signalling and kinetics of neutrophil 
extracellular trap release revealed by quantitative live imaging. Sci Rep. 2017;7(1):6529.

17. Cortjens B, de Boer OJ, de Jong R, Antonis AF, Sabogal Pineros YS, Lutter R, van Woensel JB, Bem RA. Neutrophil extracellular traps cause airway obstruction during respiratory syncytial virus disease. J Pathol. 2016;238(3):401-11.

18. Raftery MJ, Lalwani P, Krautkrmer E, Peters T, Scharffetter-Kochanek K, Kruger R, Hofmann J, Seeger K, Kruger DH, Schonrich G. beta2 integrin mediates hantavirus-induced release of neutrophil extracellular traps. J Exp Med. 2014;211(7):1485-97.

19. Jenne CN, Wong CH, Zemp FJ, McDonald B, Rahman MM, Forsyth PA, McFadden G, Kubes P. Neutrophils recruited to sites of infection protect from virus challenge by releasing neutrophil extracellular traps. Cell Host Microbe. 2013;13(2):169-80.

20. Sung PS, Huang TF, Hsieh SL. Extracellular vesicles from CLEC2-activated platelets enhance dengue virus-induced lethality via CLEC5A/TLR2. Nat Commun. 2019;10(1):2402.

21. Zuo Y, Yalavarthi S, Shi H, Gockman K, Zuo M, Madison JA, Blair CN Weber A, Barnes BJ, Egeblad M, Woods R, et al. Neutrophil extracellular traps in COVID-19. JCI Insight. 2020.

22. Yaqinuddin A, Kvietys P, Kashir J. COVID-19: Role of neutrophil extracellular traps in acute lung injury. Respir Investig. 2020;58(5):419-20.

23. Middleton EA, He XY, Denorme F, Campbell RA, Ng D, Salvatore SP, Mostyka M, Baxter-Stoltzfus A, Borczuk AC, Loda M, et al. Neutrophil extracellular traps contribute to immunothrombosis in COVID-19 acute respiratory distress syndrome. Blood. 2020;136(10):1 169-79.

24. Tomar B, Anders HJ, Desai J, Mulay SR. Neutrophils and Neutrophil Extracellular Traps Drive Necroinflammation in COVID-19. Cells. 2020;9:6.

25. Leppkes M, Knopf J, Naschberger E, Lindemann A, Singh J, Herrmann I, Sturzl M, Staats L, Mahajan A, Schauer C, et al. Vascular occlusion by neutrophil extracellular traps in COVID-19. EBioMedicine. 2020;58:102925

26. Makatsariya A, Slukhanchuk E, Bitsadze V, Khizroeva J, Tretyakova M, Tsibizova V, Tsibizova V, Dobryakov A, Elalamy I, Gris JC. COVID-19, neutrophil extracellular traps and vascular complications in obstetric practice. J Perinat Med. 2020;48(9):985-94.

27. Escalard S, Maier B, Redjem H, Delvoye F, Hebert S, Smajda S, Ciccio G, Desilles JP, Mazighi M, Blanc R, et al. Treatment of Acute Ischemic Stroke due to Large Vessel Occlusion With COVID-19: Experience From Paris. Stroke. 2020:STROKEAHA120030574.

28. Veras FP, Pontelli MC, Silva CM, Toller-Kawahisa JE, de Lima M, Nascimento DC, Schneider AH, Caetite D, Tavares LA, Paiva IM, et al. SARS-CoV-2-triggered neutrophil extracellular traps mediate COVID-19 pathology. J Exp Med. 2020;217:12.

29. Thierry AR, Roch B. Neutrophil extracellular traps and by-products play a key role in COVID-19: pathogenesis, risk factors, and therapy. J Clin Med. 2020;9:9.

30. Tripathi S, Verma A, Kim EJ, White MR, Hartshorn KL. LL-37 modulates human neutrophil responses to influenza A virus. J Leukoc Biol. 2014;96(5):931-8.

31. Caudrillier A, Kessenbrock K, Gilliss BM, Nguyen JX, Marques MB, Monestier M, Toy P, Werb Z, Looney MR. Platelets induce neutrophil extracellular traps in transfusion-related acute lung injury. J Clin Invest. 2012;122(7):2661-71.

32. Maugeri N, Campana L, Gavina M, Covino C, De Metrio M, Panciroli C, Maiuri L, Maseri A, D'Angelo A, Bianchi ME, et al. Activated platelets present high mobility group box 1 to neutrophils, inducing autophagy and promoting the extrusion of neutrophil extracellular traps. J Thromb Haemost. 2014;12(12):2074-88.

33. Kim SJ, Jenne CN. Role of platelets in neutrophil extracellular trap (NET) production and tissue injury. Semin Immunol. 2016;28(6):546-54.

34. Cox D, Kerrigan SW, Watson SP. Platelets and the innate immune system: mechanisms of bacterial-induced platelet activation. J Thromb Haemost. 2011;9(6):1097-107.

35. Clark SR, Ma AC, Tavener SA, McDonald B, Goodarzi Z, Kelly MM, Patel KD, Chakrabarti S, MCAvoy E, Sinclair GD, et al. Platelet TLR4 activates neutrophil extracellular traps to ensnare bacteria in septic blood. Nat Med. 2007;13(4):463-9.

36. Pulavendran S, Rudd JM, Maram P, Thomas PG, Akhilesh R, Malayer JR, Chow VTK, Teluguakula N. Combination therapy targeting platelet activation and virus replication protects mice against lethal influenza pneumonia. Am J Respir Cell Mol Biol. 2019;61 (6):689-701.

37. Koupenova M, Corkrey HA, Vitseva O, Manni G, Pang CJ, Clancy L, Yao C, Rade J, Levy D, Wang JP, Finberg RW, et al. The role of platelets in mediating a response to human influenza infection. Nat Commun. 2019;10(1):1780.

38. Hottz ED, Lopes JF, Freitas C, Valls-de-Souza R, Oliveira MF, Bozza MT, Da Poian AT, Weyrich AS, Zimmerman GA, Bozza FA, et al. Platelets mediate increased endothelium permeability in dengue through NLRP3-inflammasome activation. Blood. 2013;122(20):3405-14.

39. Balaphas A, Meyer J, Sadoul K, Fontana P, Morel P, Gonelle-Gispert C, Buhler LH. Platelets and platelet-derived extracellular vesicles in liver physiology and disease. Hepatol Commun. 2019;3(7):855-66.

40. van Niel G, D'Angelo G, Raposo G. Shedding light on the cell biology of extracellular vesicles. Nat Rev Mol Cell Biol. 2018;19(4):213-28.

41. Tkach M, Thery C. Communication by extracellular vesicles: where we are and where we need to go. Cell. 2016;164(6):1226-32.

42. Rodrigues M, Fan J, Lyon C, Wan M, Hu Y. Role of extracellular vesicles in viral and bacterial infections: pathogenesis, diagnostics, and therapeutics. Theranostics. 2018:8(10):2709-21.

43. Urbanelli L, Buratta S, Tancini B, Sagini K, Delo F, Porcellati S, Emiliani C. The role of extracellular vesicles in viral infection and transmission. Vaccines (Basel). 2019;7:3.

44. Schorey JS, Harding CV. Extracellular vesicles and infectious diseases: new complexity to an old story. J Clin Invest. 2016;126(4):1181-9.

45. Tao SC, Guo SC, Zhang CQ. Platelet-derived extracellular vesicles: an emerging therapeutic approach. Int J Biol Sci. 2017;13(7):828-34.

46. Sims PJ, Faioni EM, Wiedmer T, Shattil SJ. Complement proteins C5b-9 cause release of membrane vesicles from the platelet surface that are enriched in the membrane receptor for coagulation factor $V a$ and express prothrombinase activity. J Biol Chem. 1988;263(34):18205-12.

47. Robbins PD, Morelli AE. Regulation of immune responses by extracellular vesicles. Nat Rev Immunol. 2014;14(3):195-208.

48. Wang $\mathrm{H}$, Wang $Z \mathrm{ZH}$, Kong J, Yang MY, Jiang GH, Wang XP, Zhong $M$, Zhang Y, Deng JT, Zhang W. Oxidized low-density lipoprotein-dependent platelet-derived microvesicles trigger procoagulant effects and amplify oxidative stress. Mol Med. 2012;18:159-66.

49. Gomez RM, Lopez Ortiz AO, Schattner M. Platelets and extracellular traps in infections. Platelets. 2020;1:1-9.

50. Perez-Toledo M, Beristain-Covarrubias N. A new player in the game: platelet-derived extracellular vesicles in dengue hemorrhagic fever. Platelets. 2020;1:1-3.

51. Mishra R, Lata S, Ali A, Banerjea AC. Dengue haemorrhagic fever: a job done via exosomes? Emerg Microbes Infect. 2019;8(1):1626-35.

52. Lee RT, Ichikawa Y, Fay M, Drickamer K, Shao MC, Lee YC. Ligand-binding characteristics of rat serum-type mannose-binding protein (MBP-A) Homology of binding site architecture with mammalian and chicken hepatic lectins. J Biol Chem. 1991;266(8):4810-5.

53. Engering AJ, Cella M, Fluitsma D, Brockhaus M, Hoefsmit EC, Lanzavecchia A, Pieters J. The mannose receptor functions as a high capacity and broad specificity antigen receptor in human dendritic cells. Eur 」 Immunol. 1997;27(9):2417-25.

54. Chen ST, Lin YL, Huang MT, Wu MF, Cheng SC, Lei HY, Lee CK, Chiou TW, Wong CH, Hsieh SL. CLEC5A is critical for dengue-virus-induced lethal disease. Nature. 2008:453(7195):672-6.

55. Tsai TY, Huang MT, Sung PS, Peng CY, Tao MH, Yang HI, Chang WC, Yang AS, Yu CM, Lin YP, et al. SIGLEC-3 (CD33) serves as an immune checkpoint receptor for HBV infection. J Clini Investi. 2021.

56. Van Breedam W, Pohlmann S, Favoreel HW, de Groot RJ, Nauwynck HJ. Bitter-sweet symphony: glycan-lectin interactions in virus biology. FEMS Microbiol Rev. 2014;38(4):598-632.

57. da Silva LC, Mendonca JSP, de Oliveira WF, Batista KLR, Zagmignan A, Viana IFT, Correia MT. Exploring lectin-glycan interactions to combat COVID-19: Lessons acquired from other enveloped viruses. Glycobiology 2021;31(4):358-71.

58. Lu Q, Liu J, Zhao S, Gomez Castro MF, Laurent-Rolle M, D'ong J, Abbondanza M, Ran X, Damani-Yokota P, Tang H, et al. SARS-CoV-2 exacerbates proinflammatory responses in myeloid cells through C-type lectin receptors and Tweety family member 2. Immunity. 2021.

59. Figdor CG, van Kooyk Y, Adema GJ. C-type lectin receptors on dendritic cells and Langerhans cells. Nat Rev Immunol. 2002;2(2):77-84. 
60. Chaipan C, Soilleux EJ, Simpson P, Hofmann H, Gramberg T, Marzi A, Geier M, Stewart EA, Eisemann J, Steinkasserer A, et al. DC-SIGN and CLEC-2 mediate human immunodeficiency virus type 1 capture by platelets. J Virol. 2006;80(18):8951-60.

61. Suzuki-Inoue K, Fuller GL, Garcia A, Eble JA, Pohlmann S, Inoue O, Kashiwagi H, Tomiyama Y, Yatomi Y, Umemura K, et al. A novel Syk-dependent mechanism of platelet activation by the C-type lectin receptor CLEC-2. Blood. 2006;107(2):542-9.

62. van Kooyk Y, Engering A, Lekkerkerker AN, Ludwig IS, Geijtenbeek TB. Pathogens use carbohydrates to escape immunity induced by dendritic cells. Curr Opin Immunol. 2004;16(4):488-93.

63. Phoenix I, Nishiyama S, Lokugamage N, Hill TE, Huante MB, Slack OA, Carpio VH, Freiberg AN, Ikegami T. N-Glycans on the Rift Valley Fever Virus Envelope Glycoproteins Gn and Gc Redundantly Support Viral Infection via DC-SIGN. Viruses. 2016;8:5.

64. Johnson TR, McLellan JS, Graham BS. Respiratory syncytial virus glycoprotein G interacts with DC-SIGN and L-SIGN to activate ERK1 and ERK2. J Virol. 2012;86(3):1339-47.

65. Alen MM, Dallmeier K, Balzarini J, Neyts J, Schols D. Crucial role of the $\mathrm{N}$-glycans on the viral E-envelope glycoprotein in DC-SIGN-mediated dengue virus infection. Antiviral Res. 2012;96(3):280-7.

66. Martina BE, Koraka P, van den Doel P, Rimmelzwaan GF, Haagmans BL, Osterhaus AD. DC-SIGN enhances infection of cells with glycosylated West Nile virus in vitro and virus replication in human dendritic cells induces production of IFN-alpha and TNF-alpha. Virus Res. 2008;135(1):64-71.

67. Marzi A, Moller P, Hanna SL, Harrer T, Eisemann J, Steinkasserer A, et al. Analysis of the interaction of Ebola virus glycoprotein with DC-SIGN (dendritic cell-specific intercellular adhesion molecule 3-grabbing nonintegrin) and its homologue DC-SIGNR. J Infect Dis. 2007;196(Suppl 2):S237-46.

68. Marzi A, Gramberg T, Simmons G, Moller P, Rennekamp AJ, Krumbiegel M, Geier M, Eisemann J, Turza N, Saunier B, et al. DC-SIGN and DC-SIGNR interact with the glycoprotein of Marburg virus and the $S$ protein of severe acute respiratory syndrome coronavirus. J Virol. 2004;78(21):12090-5.

69. de Parseval A, Su SV, Elder JH, Lee B. Specific interaction of feline immunodeficiency virus surface glycoprotein with human DC-SIGN. J Virol. 2004;78(5):2597-600.

70. Biggins JE, Yu Kimata MT, Kimata JT. Domains of macaque DC-SIGN essential for capture and transfer of simian immunodeficiency virus. Virology. 2004;324(1):194-203.

71. Pohlmann S, Zhang J, Baribaud F, Chen Z, Leslie GJ, Lin G, GranelliPiperno A, Doms RW, Rice CM, McKeating JA. Hepatitis C virus glycoproteins interact with DC-SIGN and DC-SIGNR. J Virol. 2003;77(7):4070-80.

72. Lin G, Simmons G, Pohlmann S, Baribaud F, Ni H, Leslie GJ, Haggarty BS, Bates P, Weissman D, Hoxie JA, et al. Differential N-linked glycosylation of human immunodeficiency virus and Ebola virus envelope glycoproteins modulates interactions with DC-SIGN and DC-SIGNR. J Virol. 2003;77(2):1337-46

73. Lasala F, Arce E, Otero JR, Rojo J, Delgado R. Mannosyl glycodendritic structure inhibits DC-SIGN-mediated Ebola virus infection in cis and in trans. Antimicrob Agents Chemother. 2003:47(12):3970-2.

74. Guo Y, Feinberg H, Conroy E, Mitchell DA, Alvarez R, Blixt O, Aylor ME, Weis WI, Drickamer K. Structural basis for distinct ligand-binding and targeting properties of the receptors DC-SIGN and DC-SIGNR. Nat Struct Mol Biol. 2004;1 1(7):591-8.

75. Geijtenbeek TB, Kwon DS, Torensma R, van Vliet SJ, van Duijnhoven GC, Middel J, Cornelissen IL, Nottet HS, KewalRamani VN, Littman DR, et al. DC-SIGN, a dendritic cell-specific HIV-1-binding protein that enhances trans-infection of T cells. Cell. 2000;100(5):587-97.

76. Simon AY, Sutherland MR, Pryzdial EL. Dengue virus binding and replication by platelets. Blood. 2015;126(3):378-85.

77. Tassaneetrithep B, Burgess TH, Granelli-Piperno A, Trumpfheller C, Finke J, Sun W, Eller MA, Pattanapanyasat K, Sarasombath S, Birx DL, et al. DCSIGN (CD209) mediates dengue virus infection of human dendritic cells. J Exp Med. 2003;197(7):823-9.

78. Wang P, Li M, Lu W, Zhang D, Hu Q, Liu Y. DC-SIGN promotes Japanese encephalitis virus transmission from dendritic cells to $T$ cells via virological synapses. Virol Sin. 2017;32(6):495-502.
79. Goncalves AR, Moraz ML, Pasquato A, Helenius A, Lozach PY, Kunz S. Role of DC-SIGN in Lassa virus entry into human dendritic cells. J Virol. 2013:87(21):11504-15.

80. de Witte L, Abt M, Schneider-Schaulies S, van Kooyk Y, Geijtenbeek TB. Measles virus targets DC-SIGN to enhance dendritic cell infection. J Virol. 2006;80(7):3477-86.

81. Wang SF, Huang JC, Lee YM, Liu SJ, Chan YJ, Chau YP, Chong P, Chen YM. DC-SIGN mediates avian H5N1 influenza virus infection in cis and in trans. Biochem Biophys Res Commun. 2008:373(4):561-6.

82. Regan AD, Whittaker GR. Utilization of DC-SIGN for entry of feline coronaviruses into host cells. J Virol. 2008;82(23):11992-6.

83. Martinez MG, Bialecki MA, Belouzard S, Cordo SM, Candurra NA, Whittaker GR. Utilization of human DC-SIGN and L-SIGN for entry and infection of host cells by the New World arenavirus Junin virus. Biochem Biophys Res Commun. 2013;441(3):612-7.

84. Baribaud F, Doms RW, Pohlmann S. The role of DC-SIGN and DCSIGNR in HIV and Ebola virus infection: can potential therapeutics block virus transmission and dissemination? Expert Opin Ther Targets. 2002;6(4):423-31.

85. Alvarez CP, Lasala F, Carrillo J, Muniz O, Corbi AL, Delgado R. C-type lectins DC-SIGN and L-SIGN mediate cellular entry by Ebola virus in cis and in trans. J Virol. 2002;76(13):6841-4.

86. Wang QC, Feng ZH, Nie QH, Zhou YX. DC-SIGN: binding receptors for hepatitis C virus. Chin Med J (Engl). 2004;117(9):1395-400.

87. Hsu TL, Cheng SC, Yang WB, Chin SW, Chen BH, Huang MT, Hsieh SL, Wong $\mathrm{CH}$. Profiling carbohydrate-receptor interaction with recombinant innate immunity receptor-Fc fusion proteins. J Biol Chem. 2009;284(50):34479-89.

88. Coombs PJ, Taylor ME, Drickamer K. Two categories of mammalian galactose-binding receptors distinguished by glycan array profiling. Glycobiology. 2006;16(8):1C-7C.

89. van Weelden G, Bobinski M, Okla K, van Weelden WJ, Romano A, Pijnenborg JMA. Fucoidan structure and activity in relation to anti-cancer mechanisms. Mar Drugs. 2019;17:1.

90. Huang TF, Liu CZ, Yang SH. Aggretin, a novel platelet-aggregation inducer from snake (Calloselasma rhodostoma) venom, activates phospholipase $\mathrm{C}$ by acting as a glycoprotein la/lla agonist. Biochem J. 1995:309(Pt 3):1021-7.

91. Suzuki-Inoue K, Inoue O, Ding G, Nishimura S, Hokamura K, Eto K, Kashiwagi H, Tomiyama Y, Yatomi Y, Umemura K, et al. Essential in vivo roles of the C-type lectin receptor CLEC-2: embryonic/neonatal lethality of CLEC-2-deficient mice by blood/lymphatic misconnections and impaired thrombus formation of CLEC-2-deficient platelets. J Biol Chem. 2010;285(32):24494-507.

92. Finney BA, Schweighoffer E, Navarro-Nunez L, Benezech C, Barone F, Hughes CE, Langan SA, Lowe KL, Pollitt AY, Mourao-Sa D, et al. CLEC-2 and Syk in the megakaryocytic/platelet lineage are essential for development. Blood. 2012;119(7):1747-56.

93. O'Callaghan CA. Thrombomodulation via CLEC-2 targeting. Curr Opin Pharmacol. 2009;9(2):90-5.

94. Hitchcock JR, Cook CN, Bobat S, Ross EA, Flores-Langarica A, Lowe KL, Khan M, Dominguez-Medina CC, Lax S, Carvalho-Gaspar M, et al. Inflammation drives thrombosis after Salmonella infection via CLEC-2 on platelets. J Clin Invest. 2015;125(12):4429-46.

95. Rayes J, Lax S, Wichaiyo S, Watson SK, Di Y, Lombard S, Hofmann J, Seeger K, Kruger DH, Schonrich G. The podoplanin-CLEC-2 axis inhibits inflammation in sepsis. Nat Commun. 2017;8(1):2239.

96. Lo YL, Liou GG, Lyu JH, Hsiao M, Hsu TL, Wong CH. Dengue virus infection is through a cooperative interaction between a mannose receptor and CLEC5A on macrophage as a multivalent hetero-complex. PLoS ONE. 2016;11(11):e0166474.

97. Sancho D, Joffre OP, Keller AM, Rogers NC, Martinez D, Hernanz-Falcon P, Rosewell I, Sousa C. Identification of a dendritic cell receptor that couples sensing of necrosis to immunity. Nature. 2009;458(7240):899-903.

98. Asea A, Rehli M, Kabingu E, Boch JA, Bare O, Auron PE, Stevenson MA, Calderwood SK. Novel signal transduction pathway utilized by extracellular HSP70: role of toll-like receptor (TLR) 2 and TLR4. J Biol Chem. 2002;277(17):15028-34.

99. Cappellano G, Raineri D, Rolla R, Giordano M, Puricelli C, Vilardo B, Manfredi M, Cantaluppi V, Sainaghi PP, Castello L, et al. Circulating 
platelet-derived extracellular vesicles are a hallmark of sars-Cov-2 infection. Cells. 2021;10:1.

100. Shiokawa M, Yamasaki S, Saijo S. C-type lectin receptors in anti-fungal immunity. Curr Opin Microbiol. 2017:40:123-30.

101. Wu MF, Chen ST, Yang AH, Lin WW, Lin YL, Chen NJ, Tsai IS, Li L, Hsieh SL. CLEC5A is critical for dengue virus-induced inflammasome activation in human macrophages. Blood. 2013;121(1):95-106.

102. Huang YL, Chen ST, Liu RS, Chen YH, Lin CY, Huang CH, Shu PY, Liao CL, Hsieh SL. CLEC5A is critical for dengue virus-induced osteoclast activation and bone homeostasis. J Mol Med (Berl). 2016;94(9):1025-37.

103. Chen ST, Liu RS, Wu MF, Lin YL, Chen SY, Tan DT, Chou TY, Tsai IS, Li L, Hsieh SL. CLEC5A regulates Japanese encephalitis virus-induced neuroinflammation and lethality. PLOS Pathog. 2012;8(4):e1002655.

104. Teng O, Chen ST, Hsu TL, Sia SF, Cole S, Valkenburg SA, Hsu TY, Zheng JT, Tu W, Bruzzone R, et al. CLEC5A-mediated enhancement of the inflammatory response in myeloid cells contributes to influenza virus pathogenicity in vivo. J Virol. 2017:91:1.

105. Tung YT, Wu MF, Wang GJ, Hsieh SL. Nanostructured electrochemical biosensor for th0065 detection of the weak binding between the dengue virus and the CLEC5A receptor. Nanomedicine. 2014;10(6):1335-41.

106. Joyce-Shaikh B, Bigler ME, Chao CC, Murphy EE, Blumenschein WM, Adamopoulos IE, Heyworth PG, Antonenko S, Bowman EP, Mclanahan TK, Phillips JH, Cua DJ. Myeloid DAP12-associating lectin (MDL)-1 reg Myeloid DAP12-associating lectin (MDL)-1 regulates synovial inflammation and bone erosion associated with autoimmune arthritis. J Exp Med. 2010;207(3):579-89.

107. Cheung R, Shen F, Phillips JH, McGeachy MJ, Cua DJ, Heyworth PG, Pierce RH. Activation of MDL-1 (CLEC5A) on immature myeloid cells triggers lethal shock in mice. J Clin Invest. 2011;121(11):4446-61.

108. Watanabe Y, Allen JD, Wrapp D, McLellan JS, Crispin M. Site-specific glycan analysis of the SARS-CoV-2 spike. Science. 2020.

109. Rosell A, Havervall S, von Meijenfeldt F, Hisada Y, Aguilera K, Grover SP, Lisman T, Mackman N, Thalin C. Patients With COVID-19 Have Elevated Levels of Circulating Extracellular Vesicle Tissue Factor Activity That Is
Associated With Severity and Mortality. Arterioscler Thromb Vasc Biol. 2020:ATVBAHA120315547.

110. Wu AHB, Zhang Y, Webber R. Extracellular vesicles released in blood of COVID-19 patients: mechanism for detection of cardiac troponin after myocardial injury? Biomarkers. 2020;25(8):613-5.

111. Nicolai L, Leunig A, Brambs S, Kaiser R, Weinberger T, Weigand M, Muenchhoff M, Hellmuth JC, Ledderose S, Schulz H, et al. Immunothrombotic dysregulation in COVID-19 pneumonia is associated with respiratory failure and coagulopathy. Circulation. 2020;142(12):1176-89.

112. Arcanjo A, Logullo J, Menezes CCB, et al. The emerging role of neutrophil extracellular traps in severe acute respiratory syndrome coronavirus 2 (COVID-19). Sci Rep. 2020;10(1):19630.

113. $\mathrm{Ng} \mathrm{H}$, Havervall S, Rosell A, Aguilera K, Parv K, von Meijenfeldt FA, Lisman T, Mackman N, Thalin C, Phillipson M. Circulating markers of neutrophil extracellular traps are of prognostic value in patients with COVID-19. Arterioscler Thromb Vasc Biol. 2021:41(2):988-94.

114. Zhou F, Yu T, Du R, Fan G, Liu Y, Liu Z, Xiang J, Wang Y, Song B, Gu X, et al. Clinical course and risk factors for mortality of adult inpatients with COVID-19 in Wuhan, China: a retrospective cohort study. Lancet. 2020:395(10229):1054-62

115. Klok FA, Kruip M, van der Meer NJM, Arbous MS, Gommers D, Kant KM, Kaptein FHJ, van Paassen J, Stals MAM, Huisman MV, et al. Incidence of thrombotic complications in critically ill ICU patients with COVID-19. Thromb Res. 2020;191:145-7.

116. Lefrancais E, Ortiz-Munoz G, Caudrillier A, Mallavia B, Liu F, Sayah DM, Thornton EE, Headley MB, David T, Coughlin SR, et al. The lung is a site of platelet biogenesis and a reservoir for haematopoietic progenitors. Nature. 2017;544(7648):105-9.

\section{Publisher's Note}

Springer Nature remains neutral with regard to jurisdictional claims in published maps and institutional affiliations.
Ready to submit your research? Choose BMC and benefit from:

- fast, convenient online submission

- thorough peer review by experienced researchers in your field

- rapid publication on acceptance

- support for research data, including large and complex data types

- gold Open Access which fosters wider collaboration and increased citations

- maximum visibility for your research: over $100 \mathrm{M}$ website views per year

At BMC, research is always in progress.

Learn more biomedcentral.com/submissions 